\title{
PHOTOVOLTAIC SOLAR CELL LIKE RECEIVER FOR ELECTROMAGNETIC WAVES IN VHF-UHF BANDS
}

\author{
Daniel Iulian COSTIA, Mihai Octavian POPESCU, Claudia Laurenţa POPESCU \\ Aurelian CRACIUNESCU
}

\author{
Electrical Engineering Faculty \\ University POLITEHNICA of Bucharest \\ 313 Independentei 060042 Bucharest Romania tel/fex + 040213181003 \\ mo_popescu@ rectorat.pub.ro ; claudia.popescu@ upb.ro
}

\begin{abstract}
This paper describes the photovoltaic solar cell like receiver for electromagnetic waves in VHF-UHF bands and the application of photovoltaic solar cell in planar antenna structures. The radiating patch element of a planar antenna is replaced by a solar cell. Furthermore radiating slots are built due to the cell spacing in a solar cell array. The original feature of a solar cell (DC current generation) remains, but additionally the solar cell is now able to receive and transmit electromagnetic waves, because the electromagnetic radiation is an important source of interference on the useful signals in the electric and electromagnetic devices.
\end{abstract}

$\begin{aligned} & \text { Key words : } \\ & \text { waves, }\end{aligned}$
$\begin{aligned} & \text { electromagnetic } \\ & \text { measurements, receiver, }\end{aligned}$

\section{Introduction}

A susteinable development is conditioned by preserving the environment quality, by the study and diminishing of the polluting effects. A special polluting environment category is the electromagnetic pollution which has an impact both on the aparata and on the electric/electromagnetic devices and on plants and living organisms..

An electric or electronic device is submitted to an electromagnetic aggression by the sources of perturbations from the environment and the way this works can be more or less affected. On the other hand the electric device produces itself perturbations which affect other devices and electric aparata. The perturbation is an electromagnetic phenomenon which can deteriorate the performance of a device or can affect in a dissadvantageous way the living (substance). The electromagnetic interference (EMI -ElectroMagnetic Interference) is the result of a perturbation on an electric device. The Electromagnetic Compatibility (EMC) is the capacity of a electric system to work correctly in its electromagnetic field/environment without producing in its turn perturbations on other devices in this environment. The immunity of a device is the capacity to work accordingly in the presence of a perturbation. The susceptibility represents the loss of immunity.

The electromagnetic radiation is an important source of interference on the useful signals in the electric and electromagnetic devices. The sources of electromagnetic radiation are:

- fix radio broadcasting stations, tv, radar;

- mobile broadcasting stations used in telecommunications and the technological processes;

- energetic equipments where commutation is made with or without electric bow;

- atmospheric phenomena.

In CEM technique, the electromagnetic radiation is important from two points of view:

1. Immunity. It is necessary that an electric or electromagnetic device to work in good conditions in the presence of an electric field established by standards (CEI 801). For this purpose in the laboratory electromagnetic radiations are generated having a wide range of frequency $(9 \mathrm{kHz} \ldots 1 \mathrm{GHz})$ and the amplitude of an electric field is established to which the equipment still work. 
2. The level of interference signal. When determining the experimental level of the disturbing signal it is used under conditions established by standards a reception antenna. In order to explain the way the broadcasting and reception antennae work frequently used in C.E.M. techniques it is necessary to be known before hand the theory of Hertz bi-pole radiation. Hertz bi-pole is a physics model without practical direct correspondence, but of a great importance in order to understand how the antennae work.

A solar cell or photovoltaic cell is a device that converts solar energy into electricity by the photovoltaic effect. The solar cell is a nanostructure array capable of accepting energy and producing electricity.

Autonomous communication systems often involve the use of separate solar cells and antennas, which demand a compromise in the utilization of the limited surface available area. Integrating these elements into one will save the available space and enhance the cost reduction of these stand alone communication systems.

Some authors describes the use of solar panels as antenna $[1,2,4,5]$ especially at high frecquencies radio- receiver/emitter. In these cases solar cells are main energy sources and are used in the same time as antenna.

This paper describes the application of photovoltaic solar cells as planar antenna structures. The original feature of a solar cell (DC current generation) remains, but additionally the solar cell is now able to receive and transmit electromagnetic waves. Both single solar cells as well as solar cell arrays can be used as antennas.

Using an spectrum analyzer for photovoltaic panel and photovoltaic cell we analysis and measure the signals throughout the electromagnetic spectrum.

\section{Approach}

The fotovoltaic plant can be considered a very big antenna; generation of electrical energy as a direct current source is made at a significative level of solar radiation.

As a conductive (really semiconductor) surface the impact or electrical waves must induce an electromotive force especially in the high frecquency domain.

The new approach consists of an appliance for the conversion of solar radiation energy into electric energy with at least one solar cell.

The electrically conductive contacts of the solar cell are used simultaneously as antenna for radiation and to the receipt of electromagnetic waves.

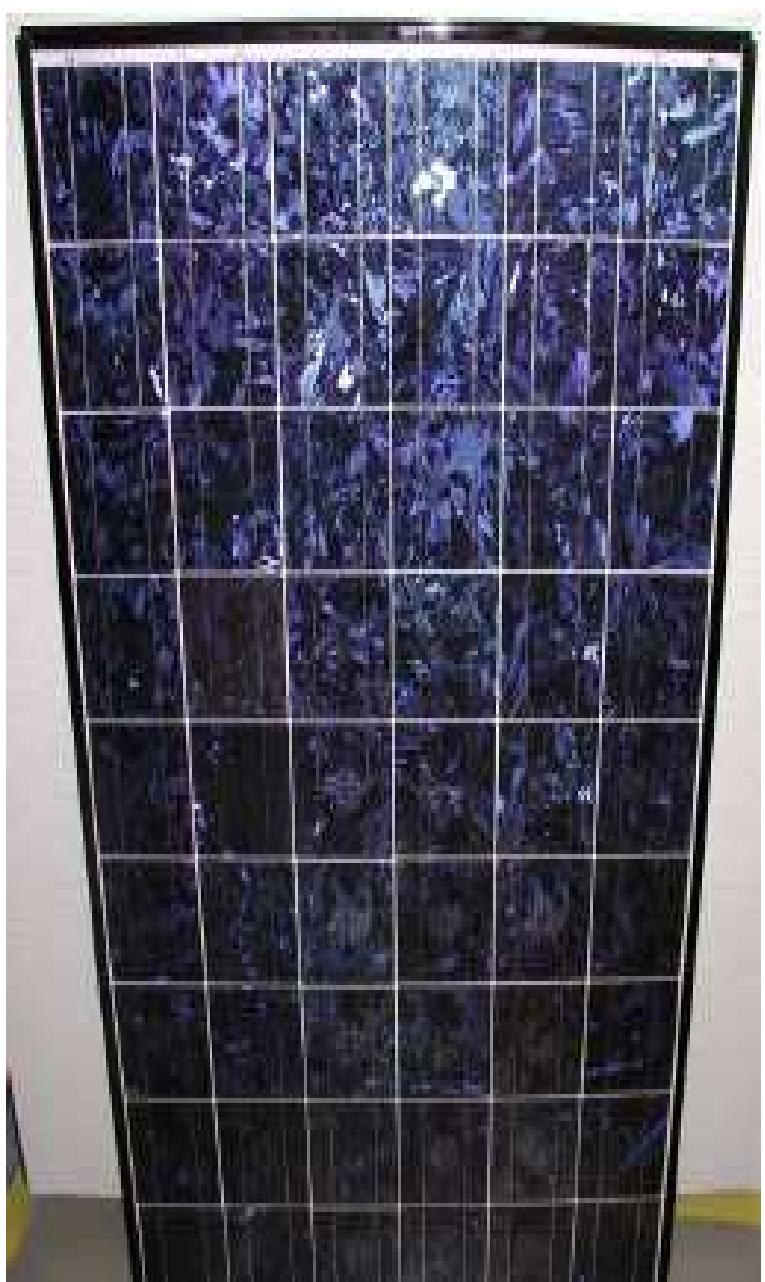

Fig. 1. Fotovoltaic solar cell (PV)

\section{Results}

Connexion of solar panel, antenna model and spectrum analyzer is shown in the figure 2 . A model of antenna is made from a conductor having a multiple $\mathrm{z}$ shape (which emulate the solar cells conexions in a planar panel) and is used as a comparative planar antenna.; see the fig. 2.b

High frecquency signals received are investigated using a spectrum analyser Rhode-Schwartz type FSH. 

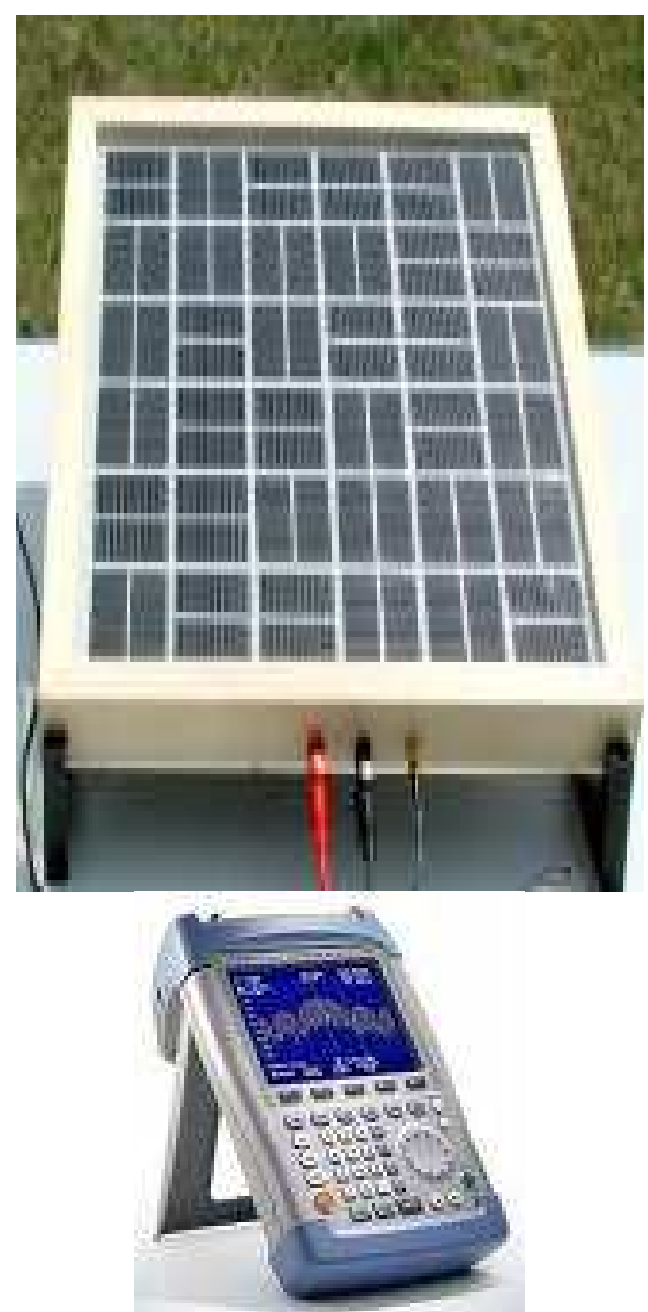

a) solar cell and receiver

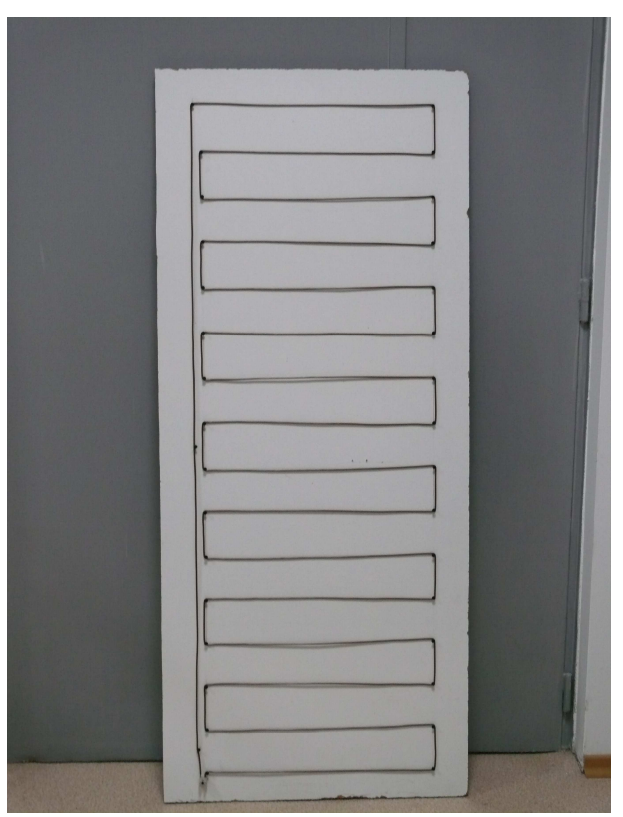

b) antenna model

Fig. 2. Circuit with solar cell, antenna model and analyzer FSH.

\subsection{Perturbations received in frequency band $1 \mathrm{MHz} \div 1 \mathrm{GHz}$.}

First of all, this frequency interval is investigated.

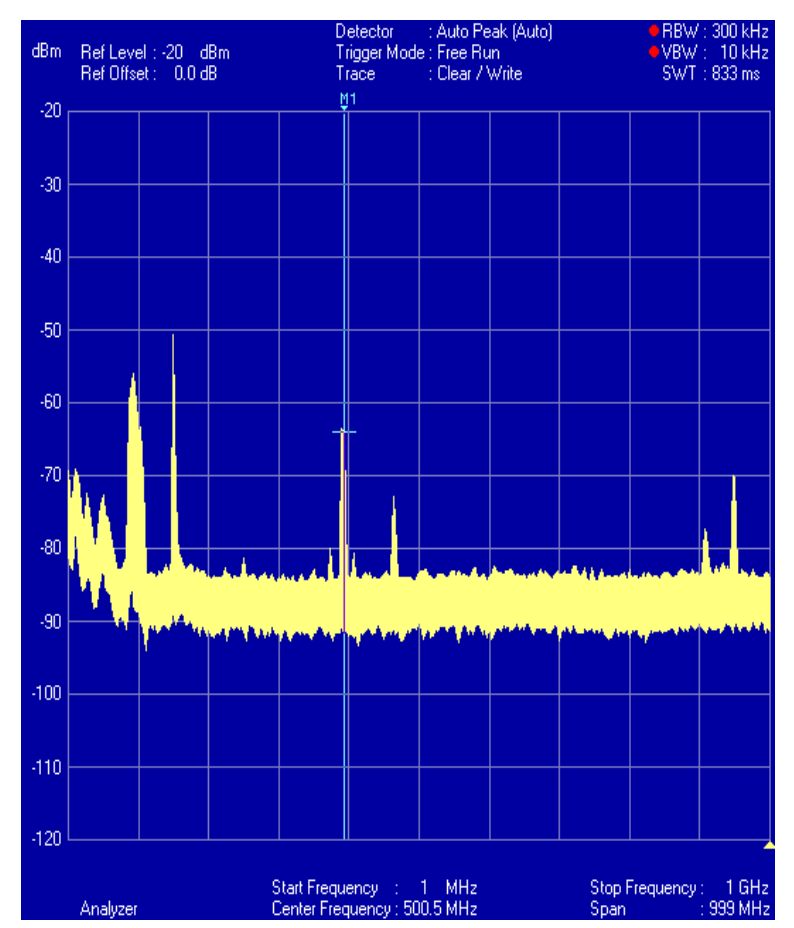

a.

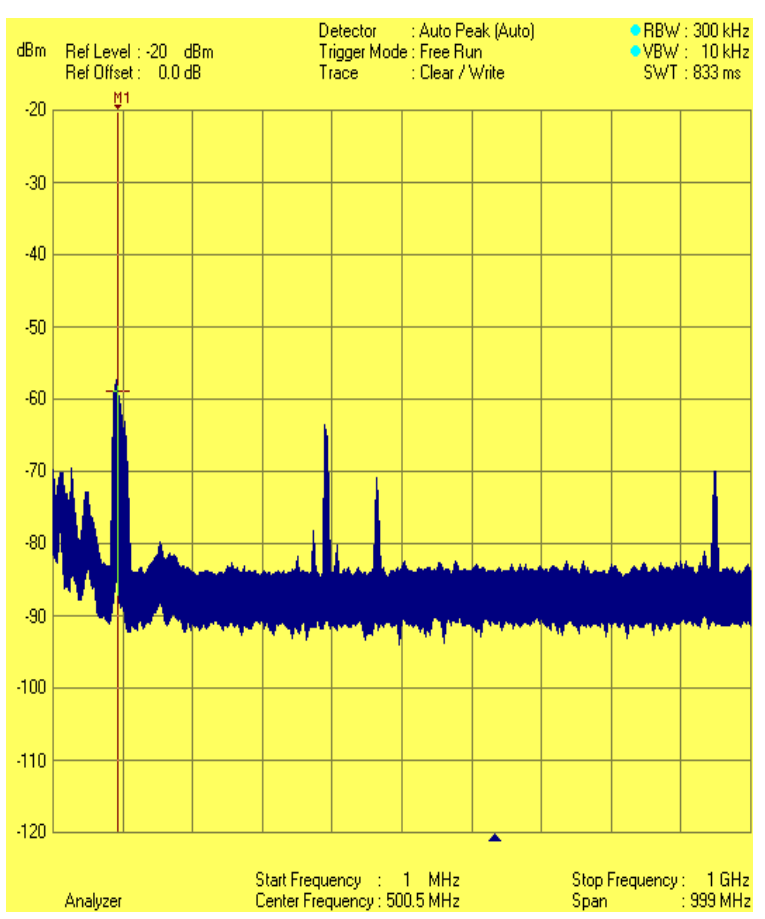

b. 


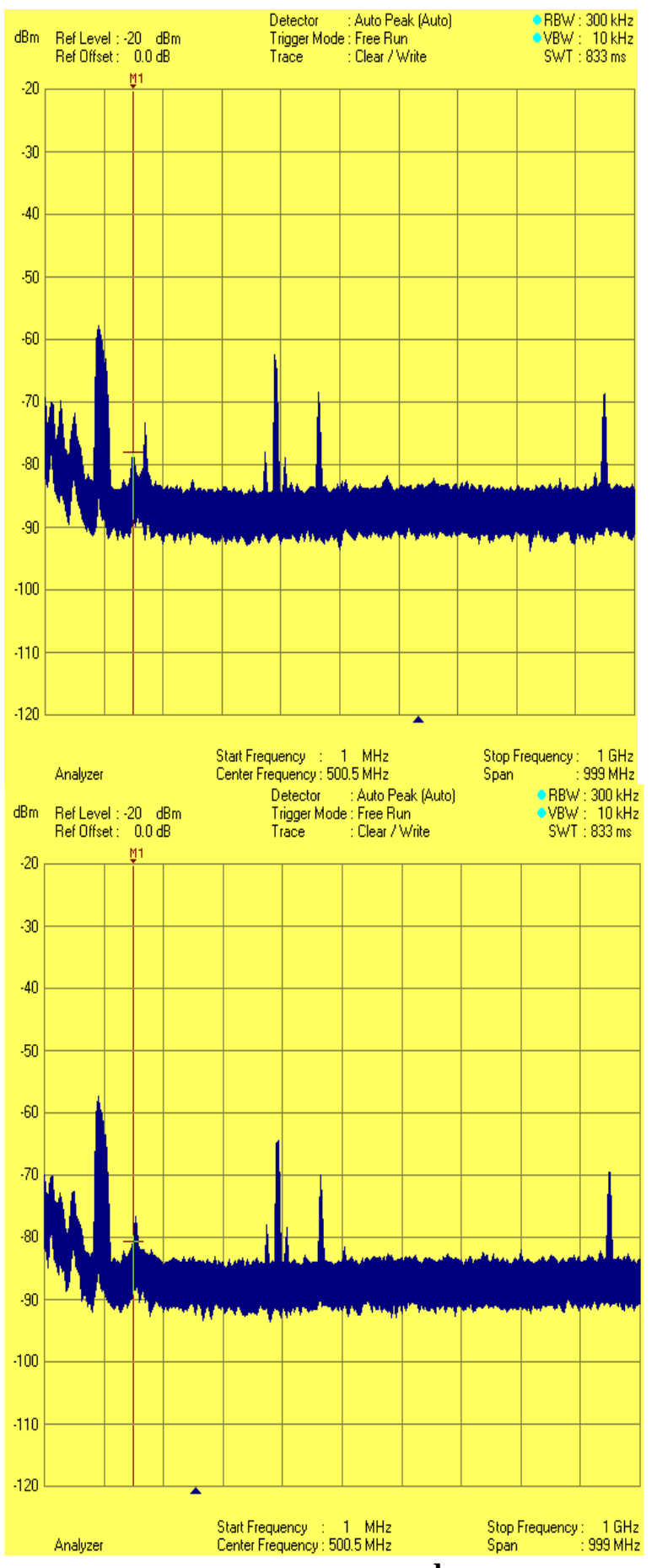

c. d.

Fig. 3. Perturbations received in frequency band $1 \mathrm{MHz}$ $\div 1 \mathrm{GHz}$

a. model of photovoltaic cell (marker $\mathrm{f}=394 \mathrm{MHz}$, level $-63,9 \mathrm{dBm})$.

b. photovoltaic cell, night (marker $\mathrm{f}=94,2 \mathrm{MHz}$, level $-58,7 \mathrm{dBm})$.

c. photovoltaic cell, sun (marker $\mathrm{f}=150,8 \mathrm{MHz}$, level $-78,2 \mathrm{dBm}$ ).

d. photovoltaic cell, inclination 45 degrees, sun (marker f $=150,8 \mathrm{MHz}$, level $-80,8 \mathrm{dBm})$.

\subsection{Perturbations received in frequency} band $85 \mathrm{MHz} \div 110 \mathrm{MHz}$ (radio).

For the model of photovoltaic cell - blue color, and for photovoltaic cell - is represented in yellow color.
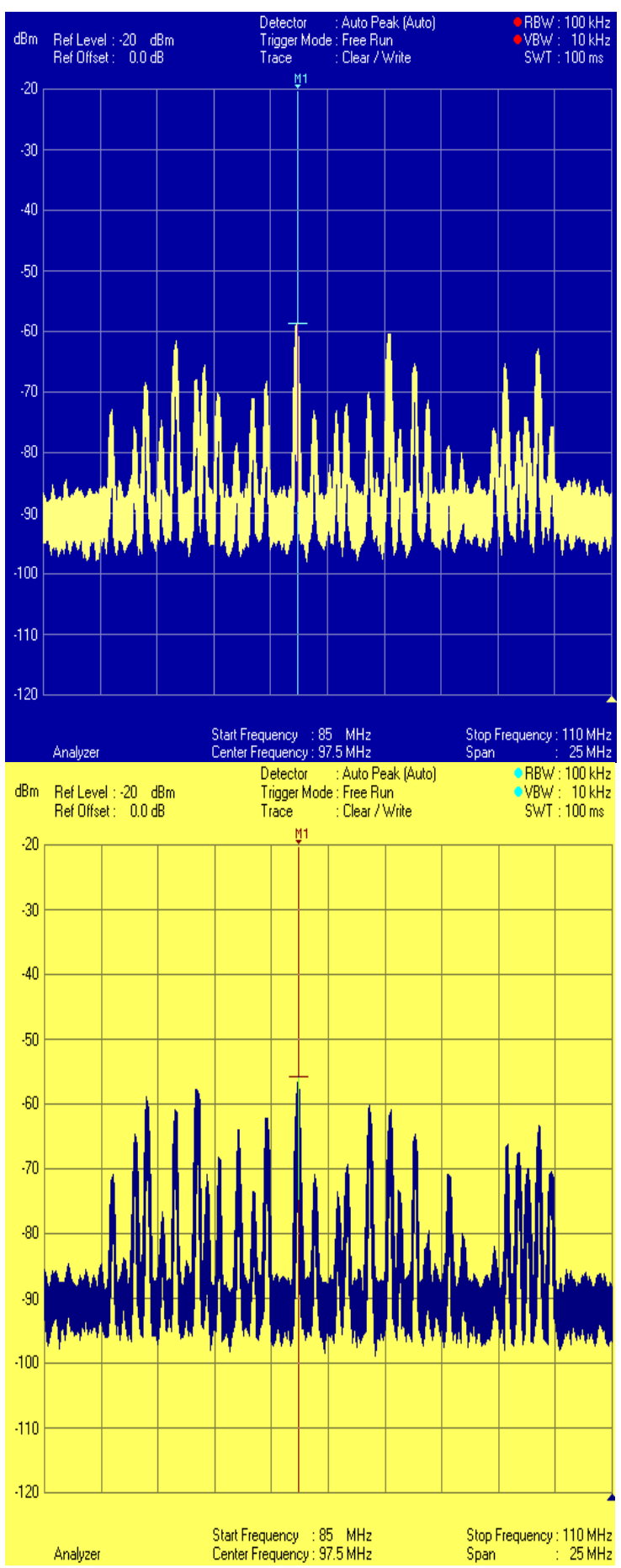

a.

b. 


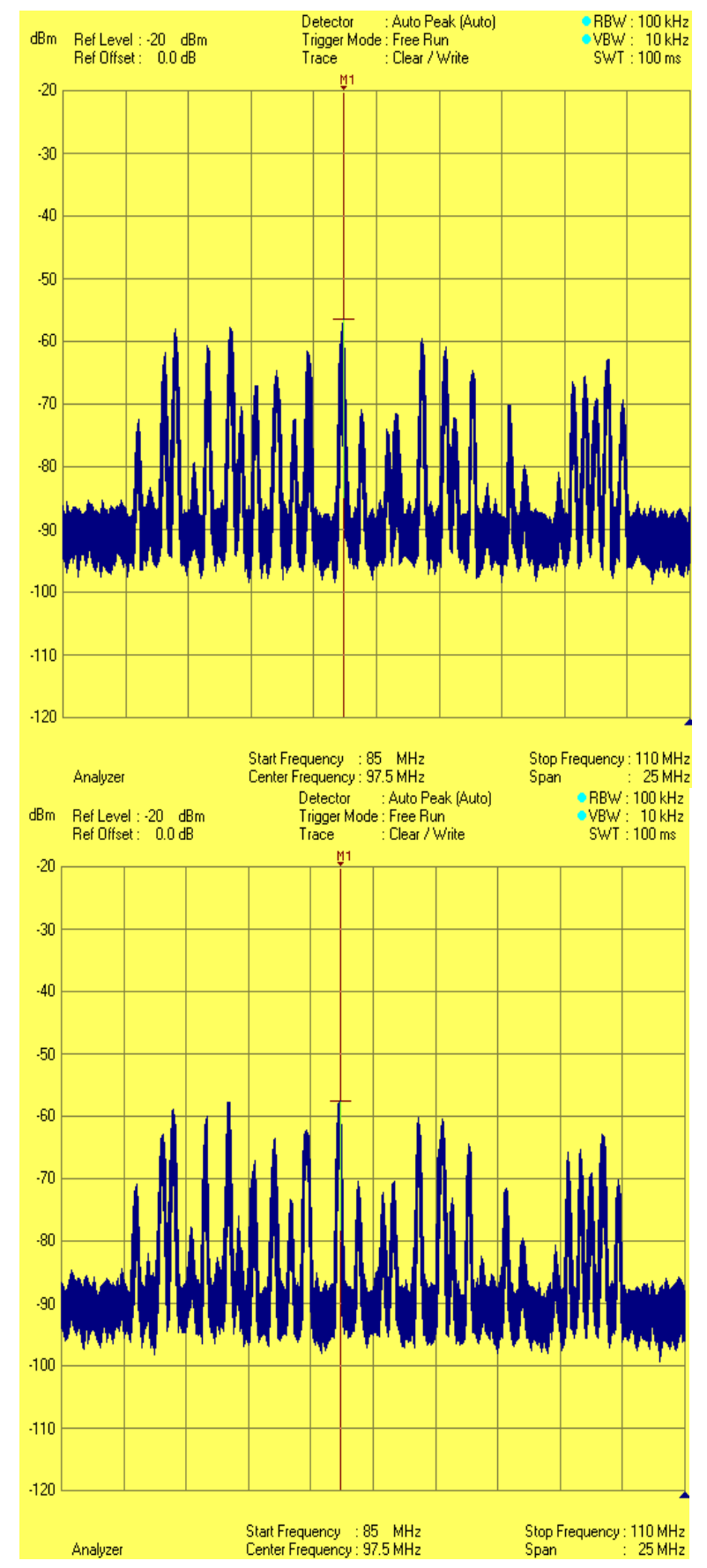

\subsection{Perturbations received in frequency band $850 \mathrm{MHz} \div 940 \mathrm{MHz}$ (GSM).}

The fixed size of the solar cells complicates the construction of a dual mode antenna (antennas both for the GSM 900 and GSM 1800 band).

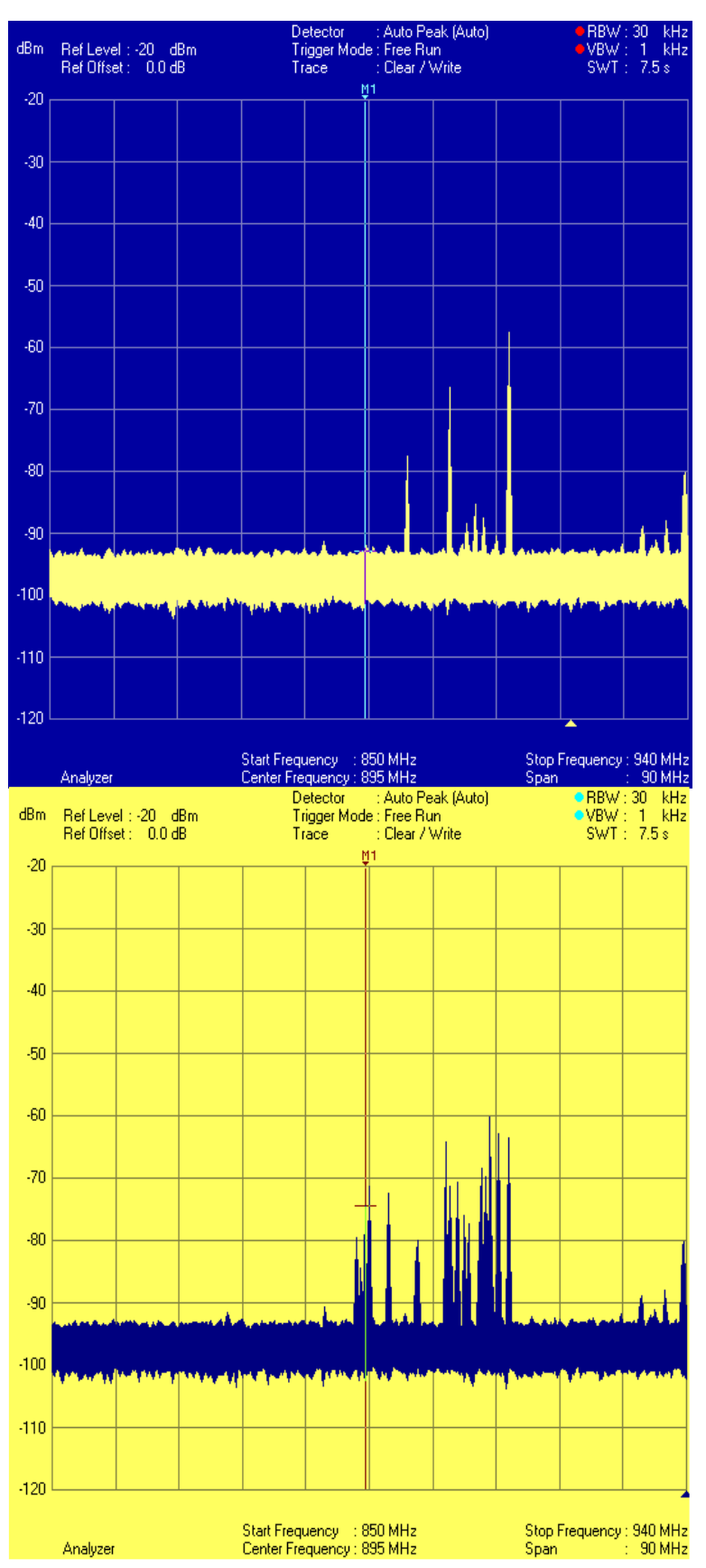

b. 


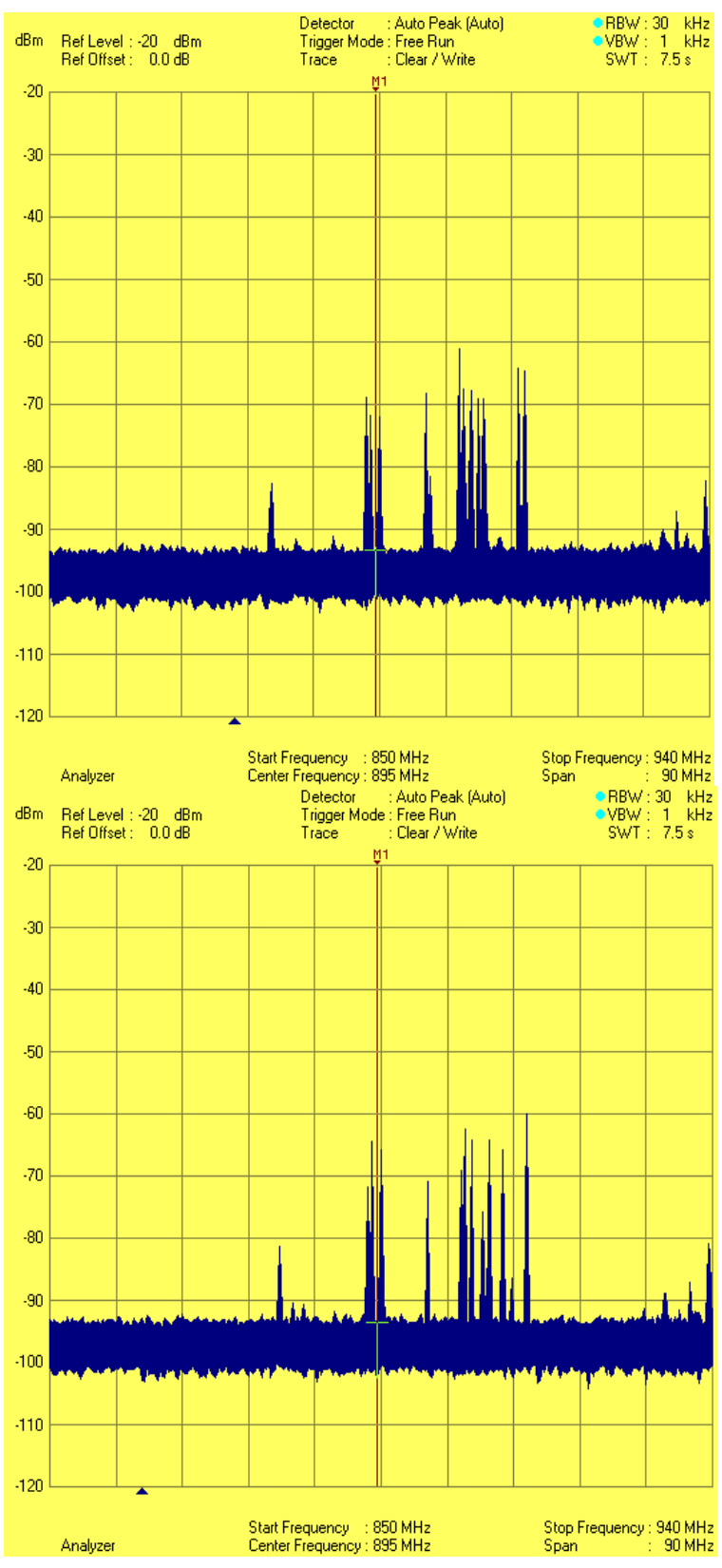

c.

d.

Fig. 5 . Perturbations received in frequency band 850 $\mathrm{MHz} \div 940 \mathrm{MHz}(\mathrm{GSM})$.

a. model of photovoltaic cell (marker $\mathrm{f}=894,5 \mathrm{MHz}$, level $-93 \mathrm{dBm}$ ).

b. photovoltaic cell, night (marker $\mathrm{f}=894,5 \mathrm{MHz}$, level $74,7 \mathrm{dBm})$.

c. photovoltaic cell, sun (marker $\mathrm{f}=894,5 \mathrm{MHz}$, level $76,5 \mathrm{dBm})$.

d. photovoltaic cell, inclination 45 degrees, sun (marker $\mathrm{f}=894,5 \mathrm{MHz}$, level -71,4 dBm).

\section{Conclusions}

The combination of photovoltaic cells and antenna technology requires special approaches because the demands of photovoltaics are often in opposite to antenna requirements. Therefore RF optimisation criteria also affect the useful surface for the solar energy conversion.

Autonomous communication systems often involve the use of separate solar cells and antennas, which demand a compromise in the utilization of the limited surface area available. Integrating these elements into one will save the available space and enhance the cost reduction of these stand alone communication systems.

The results encouraged the design of planar antennas with photovoltaic solar cells.

Photovoltaic .plants integrated in building can be used in the same time as broadcasting antennas.

The influence of illumination or the pozition (vertical or having an inclination) is not significative. The energy production is not disturbed by received signals because appropriate low-pass filters are ased.

\section{REFERENCES}

[1] N. Henze et al.: "Investigation of Planar Antennas with photovoltaic solar cells for mobile communications", The 15th IEEE International Symposium on Personal, Indoor and Mobile Radio Communications, 2004

[2] C. Bendel, N. Henze and J. Kirchhof: "Apparatus for converting solar energy into electrical energy and for radiating and/or receiving high frequency electromagnetic waves", United States Patent 6,395,971, Aug. 2000 (US), Deutsches Patent- und Markenamt, Patentschrift DE 19938199 C1, Aug. 1999 (DE).

[3] Messenger R., Ventre J. - „Photovoltaic Systems Engineering" - CRC Press London 2004, ISBN 0-8493-1793-2.

[4] Tomoyuki Wada - „Radiated electromagnetic Field from A Solar Cell” - IEEE Int. Simposium on EMC 2005, p.112-118.

[5] Bendel C. u.a - „Solar Cell Antennas in Wireless Communication and Radio Broadcast Systems" - 19 Eur. Photo. Solar Energy Conf. Paris, France, 7-11.06.2004 - 5 PV.

[5] Craciunescu A. u. a. - Monitoring results of the 30 $\mathrm{kWp}$ grid connected power system installed at University Politehnica of Bucharest, Romania ICREPQ'09 Valencia 2009 com. 473 